\title{
ANÁLISE DA VARIAÇÃO DO VOLUME DE FIBRA DE PET NA PRODUÇÃO DE CONCRETOS SUSTENTÁVEIS PARA MELHORAR SUA CAPACIDADE DE DEFORMAÇÃO*
}

\author{
Nara Caroline da Silva Rodrigues ${ }^{1}$ \\ Magnny Maisy de Barros Carvalho ${ }^{1}$ \\ Anna Victoria Morais Balbino ${ }^{1}$ \\ Adriano Luiz Roma Vasconcelos ${ }^{2}$
}

\begin{abstract}
Resumo
Assim como o crescente uso do concreto convencional, a procura por melhorias de suas características impulsiona o desenvolvimento na área científica. Uma das áreas que tem obtido avanços satisfatórios em seus resultados é a relacionada ao concreto com adição de fibras. $O$ uso da fibra de Polietileno Tereftalato (PET) foi escolhido por representar um material em excesso no meio ambiente. Busca-se além de aperfeiçoamento nas propriedades da matriz cimentícea do concreto, uma destinação sustentável para este rejeito. Conforme observado na literatura, esta adição não garante grande ganho de resistência à compressão, em contrapartida, minimiza o comportamento frágil do concreto convencional, tal como o aumento, mesmo que pouco significativo, da resistência à tração. O objetivo desta pesquisa foi avaliar o desempenho mecânico de concretos a partir da adição de fibras poliméricas na composição de concretos sustentáveis, onde buscou-se obter um concreto com propriedades mecânicas semelhantes aos concretos convencionais. Foram confeccionados concretos com os teores de $4,5 \%, 5 \%$ e $5,5 \%$ de fibras de garrafa PET. Estes concretos foram avaliados através dos ensaios de resistência à compressão axial e à tração por compressão diametral aos 28 dias.
\end{abstract}

Palavras-chave: Fibra Polimérica; PET; Concreto Sustentável; Desempenho Mecânico.

\section{ANALYSIS OF PET FIBER VOLUME VARIATION IN THE PRODUCTION OF SUSTAINABLE CONCRETES TO IMPROVE ITS DEFORMATION CAPACITY}

\begin{abstract}
As well as the growing use of conventional concrete, a search for improvements in its characteristics boosts development in the scientific field. One of the areas that has achieved satisfactory progress in its results is the relation to concrete with addition of fibers. The use of polyethylene terephthalate (PET) fiber was chosen because it represents an excess material in the environment. In addition to improving the properties of the cementitious matrix of concrete, a sustainable destination for this waste is sought. As noted in the literature, this addition does not provide great compressive strength gain, on the other hand, helps in the fight against total rupture, it minimizes the brittle behavior of conventional concrete, besides the increase, although not significant, of the traction strength. The objective of this research was to evaluate the concretes' mechanical performance from the addition of polymeric fibers in the composition of sustainable concretes, where it is sought to obtain a concrete with mechanical properties similar to conventional concretes. The concrete have been made with proportions of $4,5 \%, 5 \%$ and $5,5 \%$ of PET bottle fibers. These concretes was evaluated through tests of resistance to axial compression and to diametral compression traction at 28 days.
\end{abstract}


Keywords: Polymeric Fiber; PET; Sustainable Concrete; Mechanical Performance.

1 Graduanda em Engenharia Civil, Instituto Tocantinense Presidente Antônio Carlos, Araguaína, Tocantins, Brasil.

2 Mestre em Engenharia Civil, Professor Orientador, Instituto Tocantinense Presidente Antônio Carlos, Araguaína, Tocantins, Brasil. 


\section{INTRODUÇÃO}

A consequência de uma sociedade consumista é a degradação do meio ambiente. Com a destruição em massa das árvores para a construção de cidades sem planejamento, o índice de enchentes e secas é eminente, com isso é decorrente que as florestas e as águas reduzam. No entanto devido a essa alteração nota-se uma modificação na alteração do clima, na disponibilidade de recursos, na qualidade do ar, na pureza das águas dos rios e na quantidade de resíduo que não se degrada fácil.

A maioria dos estudos conclui que o conceito de sustentabilidade é formado por três dimensões que se conectam: econômica, ambiental e social [1]. Agora a introdução do conceito de sustentabilidade aliada ao desenvolvimento não é tarefa simples, já que a cultura consumista enraizada na sociedade atua em diferentes classes sociais.

Na prática é ainda mais dificultoso ser sustentável, pois a sociedade vive uma condição de buscas por utensílios mais rápidos, baratos e práticos em vista da defesa ambiental. Ainda, que existam tentativas de minimizar o desperdício este ato é mínimo, frente ao material que será descartado.

Inúmeras pesquisas surgem como forma de aliar o desenvolvimento construtivo à sustentabilidade, pois diante do cenário atual vê-se a necessidade de investir neste setor. Uma das inovações que agregam a essa realidade é a de adicionar fibras no concreto utilizado em obra.

As fibras usadas nessa pesquisa têm origem de garrafas usadas para armazenamento de líquidos, como refrigerante. Denominam-se garrafas PET, devido ao seu material de composição, o tereftalato de polietileno. As garrafas utilizadas na pesquisa seriam descartadas, sem o correto aproveitamento e reutilização sugeridos pelos órgãos ambientais.

Os benefícios desta adição não estão somente na minimização de resíduos sólidos e reutilização dos já existentes, mas também nos diferentes benefícios que estes podem agregar em vista das propriedades do concreto.

Além disso, a reciclagem resulta em um ganho econômico e no possível desenvolvimento social e ambiental da aplicação deste produto para ampliar os materiais construtivos de menor custo e interesse social.

\subsection{PET}

No Brasil, o volume de resíduos domésticos, nos últimos 30 anos, elevou-se em três vezes mais do que sua população. Há uma cultura de consumo que envolve o uso desordenado de embalagens descartáveis. O que alavanca por volta de 30 bilhões de toneladas de resíduos sólidos anualmente no planeta, cerca de $1 \mathrm{~kg} / \mathrm{hab}$. destes resíduos produzidos por dia. Com base nesta visão global, é necessário contornar esta realidade de imediato, pois boa parte dos dejetos domésticos não tem tomado destinos adequados. Por conseguinte, agrava ainda mais o desequilíbrio ambiental, podendo afetar até mesmo a qualidade de vida humana [2].

Em 1941, na Inglaterra, o polietileno tereftalato (PET) foi sintetizado pela primeira vez pelos químicos Whinfield e Dickson [3]. É o principal polímero da classe dos polímeros alifáticos-aromáticos. O que o torna reciclável é o fato de ser um material termoplástico que em contato com altas temperaturas e pressão, amolece e pode ser remodelado [4].

Esta descoberta tecnológica foi de grande importância para o mercado de consumo. Em razão de sua propriedade como: brilho, alta resistência à impactos e baixa 
permeabilidade, o PET, é um dos produtos mais utilizados na fabricação de embalagens. Surgiu no Brasil em 1998, conforme dados da Associação Brasileira dos Fabricantes de PET, e é um material que é amplamente produzido e descartado. Vale salientar que no Brasil a produção de PET é de 360 mil toneladas com consumo de 270 mil toneladas e a reciclagem de 89 mil toneladas [4].

Diante do cenário da desigualdade social no Brasil, a reciclagem de PET tornou-se uma fonte financeira para muitos. Os trabalhadores urbanos são os responsáveis por separar, transportar e recolher os materiais que a população descarta para então, o posterior envio às empresas de reciclagem. Por meio deste processo, o trabalhador dá uma ressignificação do lixo em mercadoria.

Contudo, é notório que este consumo é em demasia. Este hábito moderno foi adquirido no final do século XIX, em que as garrafas PET eram uma novidade em detrimento das velhas garrafas de vidro descartáveis. A praticidade deste hábito teve ascensão devido a facilidade de descarte, sem necessidade de trocas. O que, ocasionalmente, trouxe um volume muito alto de resíduos pós-consumo, o que se constitui um enorme perigo à questão ambiental atual [3].

Frente a isto, é preciso se ater a novas opções de reutilização destas embalagens, já que o descarte deixa os aterros em crescente acúmulo e sem recuperação em curto prazo, tendo em vista que a decomposição é de aproximadamente 400 anos. Um dos problemas ocasionados por isso seria a diminuição de percolação dos gases e líquidos no aterro que, significativamente, decresce a sua disposição de compactação da matéria orgânica [2].

\subsection{Compósito: O Concreto Reforçado com Fibras}

Os materiais compósitos são aqueles caracterizados pela mistura de, no mínimo, dois materiais. Sendo estes materiais ainda identificados após a mistura, afirma-se que existem duas fases: a fase matriz e a fase fibra. As matrizes servem para transferir e homogeneizar os esforços suportados pelos componentes de reforço, enquanto as fibras são os elementos de reforço que servem como ponte de transferência de cargas, além de absorver parte dos esforços, o que torna 0 processo de ruptura progressivo ao invés de ser brusco [5].

Segundo Galvão [6], o concreto não armado é um material frágil, quebradiço e possui baixa resistência aos esforços de tração. Ao adicionar fibras, mesmo que descontínuas e aleatórias ao concreto, tende-se a ter uma melhoria na resistência do mesmo, sobretudo a fissuras que ocorrem na exposição de umidade ou mudanças de temperatura do meio ambiente. As fibras permitem que o concreto resista a tensões de tração elevadas e com capacidade de deformação no estágio após a fissuração.

A quantidade de fibras incorporadas a matriz pode ser indicada pelo volume de fibras, em porcentagem, comparadas ao volume total [5]. De acordo com Mehta e Monteiro [7], a quantidade de fibras varia de acordo com o objetivo de desempenho do material. Os compósitos com baixo teor de fibra são empregados para controlar a fissuração por retração, já altas dosagens de fibra são utilizadas quando se deseja alcançar melhorias na resistência a flexão, tenacidade à fratura e na resistência ao impacto.

A relação matriz-fibra requer um trabalho em conjunto, onde a interface de encontro das duas é a responsável por transferir os esforços e pela aderência. Em virtude disso, é substancial garantir a qualidade da interface matriz-fibra [5]. Se a aderência fibra-matriz é fraca, a transferência de cargas através das fissuras é diminuída, ou seja, não aumentam a tenacidade do compósito. Se esta aderência for forte, grande 
parte das fibras pode romper antes que dissipem energia pelo arrancamento, conduzindo a uma melhoria discreta nas propriedades mecânicas [7].

Um fator que é consenso na adição de qualquer tipo de fibra é a redução da trabalhabilidade do concreto. Independente da fibra, a perda da trabalhabilidade é proporcional ao volume de concentração de fibras adicionadas ao concreto [7].

\subsection{Adição da Fibra da Garrafa Pet ao concreto}

O uso de fibras de PET como adição no concreto é uma solução que visa reduzir a quantidade de resíduo descartado no meio ambiente, agregando ao concreto melhorias em suas características mecânicas.

As fibras de PET devem ser duráveis nos materiais que tem como base o cimento. Como não existe concordância sobre a longevidade das fibras de PET nos materiais que tem como base o cimento, tem-se uma obrigação de avaliar as propriedades para se garantir o comportamento do compósito. Contudo, existe outra vantagem para a avaliação do desempenho do PET como reforço, já que elas são oriundas da reciclagem de garrafas plásticas, visto que são materiais que possuem um tempo de decomposição longo, cerca de 100 anos, o consumo delas como agregados na elaboração de argamassas e concretos ajudarão na preservação do meio ambiente. Quando são substituídos os agregados de um concreto de cimento Portland por PET, sua trabalhabilidade é alterada. Quando os teores de PET são altos têm-se uma queda de abatimento, nota-se também que o PET apresenta baixa resistência a álcalis, e não é detectado nenhum problema durante a utilização das fibras em concretos normais [8].

Depois de avaliar a resistência à tração na flexão de concretos com teores e comprimentos de fibras diferentes, Pelisser [9] notou um aumento na resistência á flexão nos concretos reforçados com fibras, e mesmo com o aumento no volume de fibras sua resistência aumentava. Ele também percebeu que não houve diferenças significativas nos ensaios de tração por compressão diametral quando as fibras de PET foram adicionadas no concreto.

É substancial a implementação de processos inovadores de reciclagem de PET. A adição de PET ao concreto pode promover um compósito com novas propriedades e que atende ao desempenho esperado, além de oportunizar uma destinação adequada deste rejeito que é tão prejudicial ao meio ambiente [6].

\section{MATERIAIS E MÉTODOS}

\subsection{Obtenção e corte das fibras de PET}

Foram recolhidas garrafas de PET de tamanhos pré-definidos que seriam descartadas, posteriormente as mesmas foram beneficiadas através de um processo de lavagem e secagem. Depois de lavadas e secadas foram aproveitadas de todas as garrafas apenas a parte mais maleável para a obtenção das fibras como demonstrado na Figura 1. Após o corte do corpo da garrafa, a mesma foi encaminhada para o filetador manual, como na Figura 2, onde foram efetuados os cortes horizontais na espessura de $5 \mathrm{~mm}$, após isso foram cortadas manualmente. A fibra assume a seguinte geometria: $10 \mathrm{~cm}$ de comprimento e $05 \mathrm{~mm}$ de largura, como ilustrado na Figura 3. 


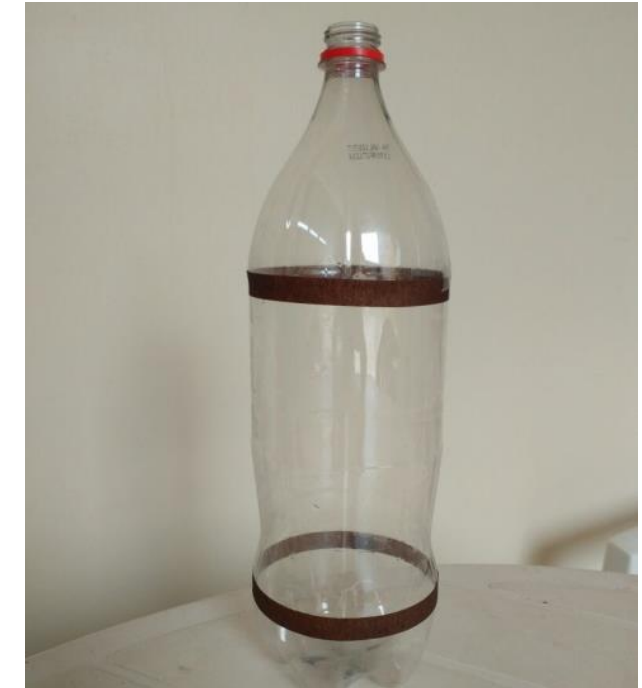

Figura 1. Aproveitamento da Garrafa PET Fonte: Autor (2017).

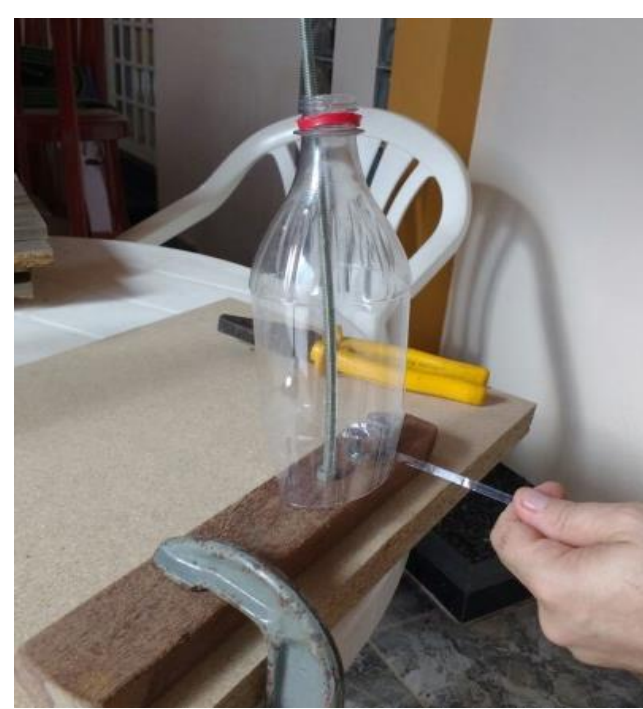

Figura 2. Corte da garrafa PET com auxílio do filetador.

Fonte: Autor (2017).

Figura 3. Fibra de PET medida com auxilio da trena.

Fonte: Autor (2017)

Realizou-se o ensaio de caracterização para possível conhecimento da característica do material, esse ensaio consistiu na presença de um recipiente de volume conhecido e uma quantidade qualquer de massa de PET pesada para o conhecimento de sua massa unitária, o cálculo de massa unitária é representado como sendo a razão da massa de fibras pelo volume do recipiente (Equação 1), seus dados especificados na Tabela 1.

$$
\gamma_{\left(\frac{\mathrm{kg}}{\mathrm{m}^{3}}\right)}=\frac{\mathrm{M}_{\text {fibras }(\mathrm{kg})}}{\mathrm{V}_{\text {recipiente }\left(\mathrm{m}^{3}\right)}}
$$

Tabela 1. Massa específica do PET

\begin{tabular}{cccc}
\hline Tipo & Volume inicial $\left(\mathbf{m}^{3}\right)$ & Massa do Agregado $\mathbf{K g})$ & Peso Específico $\left(\mathbf{K g} / \mathbf{m}^{3}\right)$ \\
\hline Amostra 01 & 0,00157 & 0,07 & 44,586 \\
\hline Amostra 02 & 0,00157 & 0,09 & 57,325 \\
\hline Amostra 03 & 0,00157 & 0,12 & 76,433 \\
\hline \multicolumn{4}{c}{ Peso específico médio $\left(\mathbf{K g} / \mathbf{m}^{3}\right)$} \\
\hline
\end{tabular}

Fonte: Autor (2017) 
A quantidade de fibras fora calculada de acordo com o conhecimento do volume do molde do corpo de prova utilizando para confecção do concreto.

\subsection{Caracterização dos agregados}

A caracterização granulométrica dos agregados foi realizada por meio do ensaio de granulometria que segue os procedimentos da NBR 7217 [10], Tabela 2. Com isso, foi possível obter o módulo de finura do agregado miúdo e diâmetro máximo do agregado graúdo demonstrados na Tabela 3.

Tabela 2. Análise granulométrica dos agregados

\begin{tabular}{|c|c|c|c|c|c|c|}
\hline \multirow{2}{*}{$\begin{array}{c}\text { Peneira } \\
\text { (mm) }\end{array}$} & \multicolumn{3}{|c|}{ Agregado Miúdo (areia) } & \multicolumn{3}{|c|}{ Agregado Graúdo (brita) } \\
\hline & (gr) & $\%$ Ret & \%Acum. & (gr) & $\%$ Ret & \%Acum. \\
\hline 19 & 90 & 9 & 9 & & & \\
\hline 12,5 & 746,67 & 74,67 & 83,67 & & & \\
\hline 9,5 & 100 & 10 & 93,67 & & & \\
\hline 6,3 & 63,33 & 6,33 & 100 & 0 & 0 & 0 \\
\hline 4,8 & & & & 0,33 & 0,07 & 0,07 \\
\hline 2,4 & & & & 3,67 & 0,73 & 0,8 \\
\hline 0,6 & & & & 128,3 & 25,66 & 26,46 \\
\hline 0,3 & & & & 320,9 & 64,18 & 90,64 \\
\hline 0,15 & & & & 43,07 & 8,61 & 99,25 \\
\hline fundo & 0 & 0 & 100 & 3 & 0,6 & 99,85 \\
\hline Total & 1000 & 100 & 200 & 499,27 & 99,85 & 199,71 \\
\hline
\end{tabular}

Tabela 3. Dimensões dos Agregados

\begin{tabular}{ccc}
\hline & $\begin{array}{c}\text { Agregado } \\
\text { Miúdo }\end{array}$ & $\begin{array}{c}\text { Agregado } \\
\text { Graúdo }\end{array}$ \\
\hline $\begin{array}{c}\text { Módulo } \\
\text { de finura }\end{array}$ & 1,99 & - \\
\hline $\begin{array}{c}\text { Diâmetro } \\
\text { Máximo }\end{array}$ & - & 12,5 \\
\hline
\end{tabular}

Fonte: Autor (2017)

A massa especifica do agregado miúdo apresentou o valor de $2670 \mathrm{Kg} / \mathrm{cm}^{3}$, enquanto a do agregado graúdo foi de $2810 \mathrm{Kg} / \mathrm{cm}^{3}$, conforme a NBR 9776 [11]. E com respaldo na NBR NM 45 [12] , os valores encontrados para massa unitária do agregado miúdo foi de $1665,83 \mathrm{Kg} / \mathrm{m}^{3}$, ao passo que a do agregado graúdo aferiu-se $1772,50 \mathrm{Kg} / \mathrm{m}^{3}$.

\subsection{Preparação dos corpos de prova}

O traço utilizado foi de 1: 1,12: 2,17 a/c 0,39, calculado através do método ABCP, sendo que a adição de PET foi definida através da porcentagem em relação ao volume do molde do corpo de prova. Foram feitos 40 corpos de prova, divididos em PET 0, PET 1, PET 2 e PET 3, contendo 0\%, 4,5\%, 5\% e 5,5\% respectivamente. A moldagem foi realizada de acordo com a NBR 5738 [13], o molde utilizado tem o formato cilíndrico e possui dimensão de $10 \times 20 \mathrm{~cm}$, foi também respeitado a temperatura e umidade para o processo de cura, que teve duração de 28 dias. 


\section{RESULTADOS E DISCUSSÃO}

Os corpos de prova foram submetidos a ensaios de tração por compressão diametral e compressão axial, todos eles foram submetidos a cargas constantes até o momento da sua ruptura, de acordo com as normas vigentes para cada ensaio.

\subsection{Ensaio de Compressão Axial}

Para este ensaio utilizou-se a prensa hidráulica EMIC 23-200, do laboratório de Materiais de Construção do Centro Universitário ITPAC. Os corpos de prova foram submetidos a cargas constantes e após o rompimento utilizou-se da carga máxima aplicada para calcular o valor da tensão de compressão axial (Equação 2), de acordo com a NBR 5739 [14].

$$
F C=\frac{4 \times F}{\pi \times D^{2}}
$$

Onde se tem que Fc é a resistência à compressão, em $\mathrm{MPa}$; $\mathrm{F}$ é a força máxima alcançada, em $\mathrm{N}$ e $\mathrm{D}$ é o diâmetro do corpo de prova, em $\mathrm{mm}$.

Através desta fórmula, foi possível calcular a resistência característica para cada dosagem de fibra de PET, inclusive a do traço referência sem a fibra de PET. De acordo com a Figura 4 nota-se uma queda considerável de desempenho mecânico nos corpos de prova que continham a fibra de PET.

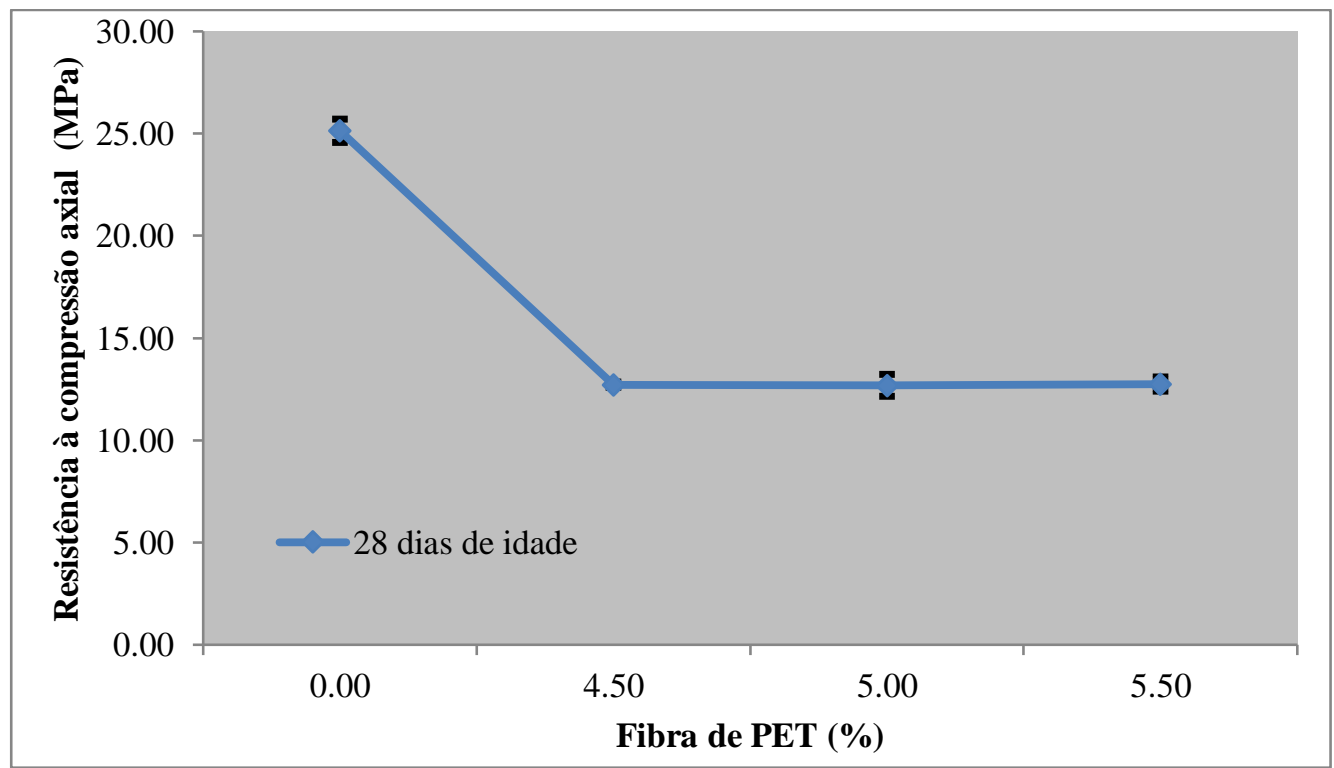

Figura 4. Resistência à compressão axial. Fonte: Autor (2017)

\subsection{Ensaio de Tração por Compressão Diametral}

Este ensaio foi feito de acordo com a NBR 7222 [15] e foi feito no laboratório de Materiais de Construção do Centro Universitário ITPAC com auxilio da prensa hidráulica EMIC 23-200.

Os corpos de prova são submetidos a cargas constantes de compressão até a sua ruptura, utilizando-se da carga máxima aplicada, calcula-se a resistência a tração, através da Equação 3:

$$
F_{c t, s p}=\frac{2 \times F}{\pi x d \times l}
$$


Onde se tem que $F_{c t, s p}$ é a resistência de tração por compressão diametral, em Mpa; $\mathrm{F}$ é a força máxima aplicada, em $\mathrm{N}$; d é o diâmetro do corpo de prova, em $\mathrm{mm}$ e l é o comprimento do corpo de prova, em $\mathrm{mm}$.

Os valores encontrados podem ser observados na Figura 5, onde também se observa o aumento da resistência à tração, esse fator pode ser explicado pela característica da fibra de ser reforço e ponte de transferência para os esforços aplicados.

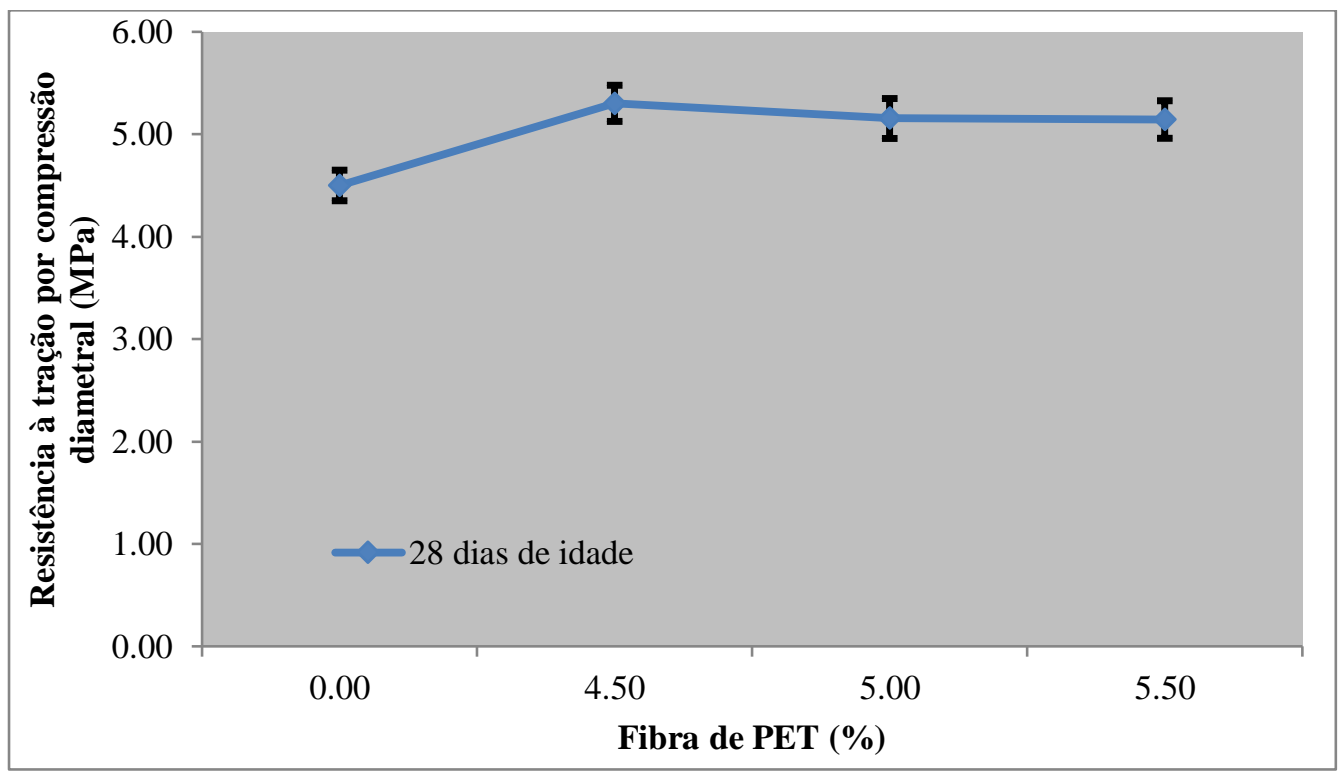

Figura 5. Resistência à tração por compressão diametral.

Fonte: Autor (2017)

Além da resistência a tração, também foi perceptível que ao romper o corpo de prova não houve a ruptura global da peça, pois a fibra continuou atuando na ligação dos elementos, conforme se pode analisar na Figura 6:

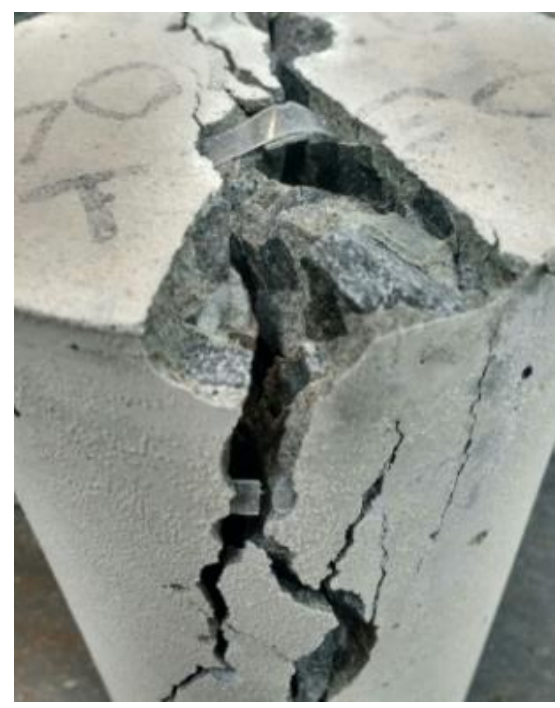

Figura 6. Corpo de prova após a ruptura na prensa.

Fonte: Autor (2017) 


\section{CONCLUSÃO}

Após a análise dos resultados, percebe-se que a incorporação de fibra de PET na produção de concretos sustentáveis influenciou na melhoria da capacidade de deformação do compósito elaborado. Haja vista que ocorreu aumento considerável nos valores de resistência à tração do concreto com adição da fibra em relação ao concreto sem esta adição. No entanto, o compósito não apresentou ganho de resistência à compressão, em detrimento do concreto tido como referência.

Ademais, identificou-se que ao comparar o ganho de tensão à tração entre as diferentes porcentagens de fibras de PET desenvolvidas (4,5; 5 e 5,5\%), não se obteve variações significativas, aos 28 dias de cura.

\section{REFERÊNCIAS}

1 CLARO, P. B. O.; CLARO, D. P.; AMÂNCIO, R. Entendendo o conceito de sustentabilidade nas organizações. Revista Administração. São Paulo, v.43, n.4, p. 289-300, Out./Nov./Dez. 2008.

2 CANELLAS, S.; D'Abreu,J.. Reciclagem de PET, visando a substituição de agregado miúdo em argamassa. Rio de Janeiro,2005.

3 MODRO, N.L.R.. Desenvolvimento e Caracterização de Concreto de Cimento Porland Contendo Resíduos Poliméricos de PET. Joinville, 2008.

4 ASSOCIAÇÃO BRASILEIRA DE PET. Disponível em: <www.abipet.org.br>. Acesso em: 06 Mar. 2017.

5 IZQUIERDO, I. S.. Uso de fibra natural de sisal em blocos de concreto para alvenaria estrutural. São Carlos, 2011.

6 GALVÃO, J.. Uso de materiais poliméricos reciclados em estruturas de concreto para superfícies hidráulicas. Curitiba, 2010.

7 METHA, P. K.; MONTEIRO, P. Concreto: Microestrutura, propriedades e Materiais. 3. ed. São Paulo: IBRACON, 2014.

8 OCHI, T., OKUBO, S., FUKUI, K.. Development of recycled PET fiber and its application as concrete-reinforced fiber. Cement and Concrete Composites, v. 29, n. 6, p. 448-455, Fev. 2007.

9 PELISSER, F. Avaliação do desempenho de concreto reforçado com fibras de polietileno tereftalato. Florianópolis, 2002.

10 ASSOCIAÇÃO BRASILEIRA DE NORMAS TÉCNICAS. NBR 7217. Agregados Determinação da composição granulométrica. Rio de Janeiro, 1987.

11 ASSOCIAÇÃO BRASILEIRA DE NORMAS TÉCNICAS. NBR 9776. Agregados Determinação da massa específica Chapman. Rio de Janeiro, 1987.

12 ASSOCIAÇÃO BRASILEIRA DE NORMAS TÉCNICAS. NBR NM 45. Agregados Determinação da massa unitária e do volume de vazios. Rio de Janeiro, 2006.

13 ASSOCIAÇÃO BRASILEIRA DE NORMAS TÉCNICAS. NBR 5738. Concreto Procedimento para moldagem e cura de corpos de prova. Rio de Janeiro, 2015.

14 ASSOCIAÇÃO BRASILEIRA DE NORMAS TÉCNICAS. NBR 5739. Concreto - Ensaios de compressão de corpos-de-prova cilíndricos. Rio de Janeiro, 2007.

15 ASSOCIAÇÃO BRASILEIRA DE NORMAS TÉCNICAS. NBR 7222. Concreto e argamassa - Determinação da resistência à tração por compressão diametral de corpos de prova cilíndricos. Rio de Janeiro, 2011. 